\title{
Luta pela guarda compartilhada: narrativas dos pais
}

\author{
Débora Augusto Franco \\ Andrea Seixas Magalhães \\ Terezinha Féres-Carneiro
}

\section{RESUMO}

O presente artigo é parte de uma pesquisa mais ampla sobre a vivência de pais separados que lutam pela guarda compartilhada dos filhos. O objetivo deste estudo é investigar as repercussões da prioridade da guarda materna e o papel da guarda compartilhada como alternativa para a convivência familiar. Foram entrevistados 12 sujeitos, dez homens e duas mulheres, que relataram dificuldades de manutenção dos laços parento-filiais após o rompimento da relação conjugal. Os participantes foram recrutados diretamente em comunidades virtuais do Facebook, que funcionam como grupo de apoio para pais que brigam na justiça pela guarda compartilhada dos filhos. Dentre as principais dificuldades relatadas pelos participantes, ressaltam-se a limitação da convivência com os filhos após a separação conjugal e a morosidade da justiça na tomada de decisão nos processos de guarda compartilhada. Conclui-se que é preciso construir suportes sociais, culturais, jurídicos e políticos capazes de desfazer o estereótipo da mulher como cuidadora melhor habilitada, assim como do homem como auxiliar-provedor na relação parento-filial.

Palavras-chave: guarda compartilhada; parentalidade; convivência familiar; separação conjugal.

\section{ABSTRACT}

\section{The fight for joint custody: the Narrative of Parents}

The present article is part of a broader research about the experience of divorced parents who fight for the joint custody of their children. The purpose of this study is to investigate the repercussions of prioritizing the custody of the mother over the father, and the role of joint custody as an alternative to family life. The authors interviewed 12 subjects -10 men and 2 women - who described difficulties in maintaining parent-child bonds after the end of the conjugal relationship. The authors recruited participants online, from Facebook pages that serve as a support network for parents who fight in the legal system for the joint custody of their children. Among the main hardships mentioned by the participants, stand out the limitation of family life with their children after the conjugal separation and the slow pace of the legal system regarding rulings over joint custody claims. The authors conclude that it is necessary to build social, cultural, legal, and political support systems capable of deconstructing the stereotype of the woman as a better caretaker than the man, as well as the one of the man as a helper-provider in the parent-child relationship.

Keywords: joint custody; parenthood; family life; conjugal separation.

No Brasil, as famílias que protagonizam a separação conjugal podem administrar a divisão de responsabilidade no que tange os cuidados físicos e psicológicos com os filhos. Para isso foi sancionada em 2014 a lei sobre o significado do termo "guarda compartilhada" e suas aplicações (Lei n 13.058 de 2014), que promove a ampliação da convivência entre pais e filhos após a separação conjugal. A respectiva lei, que substituiu a anterior, $n^{\circ} 11.698$ de 2008, instituiu a guarda compartilhada no Brasil, diligenciando as relações conjugais a partir de uma nova perspectiva.

\section{Sobre os Autores}

D. A. F.

orcid.org/0000-0002-8302-1549

Pontifícia Universidade Católica do Rio de Janeiro (PUC-Rio) -

Rio de Janeiro, RJ

deboraugusto@yahoo.com.br

\section{A. S. M.}

orcid.org/0000-0003-2992-9844 Pontifícia Universidade Católica do Rio de Janeiro (PUC-Rio) -

Rio de Janeiro, RJ

andreasm@puc-rio.br

T. F. C.

orcid.org/0000-0002-0564-7810

Pontifícia Universidade Católica do Rio de Janeiro (PUC-Rio) -

Rio de Janeiro, RJ

teferca@puc-rio.br

\section{Direitos Autorais}

Este é um artigo de acesso aberto e pode ser reproduzido livremente, distribuído,

transmitido ou modificado, por qualquer pessoa desde que usado sem fins comerciais. 0 trabalho é disponibilizado sob a licença Creative Commons CCBY-NC. 


\section{- INTERACÃO EM ET PSICOLOGIA}

Débora Augusto Franco, Andrea Seixas Magalhães e Terezinha Féres-Carneiro

A lei da guarda compartilhada também foi motivada pelo desejo de muitos pais em partilhar a criação e a educação dos filhos e contou com atuação ativa de associações, tais como a "Associação de pais e mães separados" (APASE) e a "Associação Pais Para Sempre", que encaminharam, em 2002, um pré-projeto de lei que tratava da guarda compartiIhada. O projeto, após tramitação no Congresso Nacional, acabou por resultar na alteração dos artigos 1583 e 1584 do Código Civil (Lei no 11.698 de 2008), que passou a vigorar com uma nova redação, indicando a adoção da guarda compartilhada objetivando privilegiar o melhor interesse da criança e a igualdade parental, sendo considerada uma resposta eficaz à continuidade das relações dos filhos com os pais após a separação conjugal (Brito \& Gonsalves, 2013).

As leis anteriores, segundo alguns especialistas (Barros, 2001; Brandão, 2011; Brito, 2007; 2014; Shine, 2010), fortaleceram a ideia de que os cuidados físicos, psicológicos, afetivos e sociais deveriam ser de responsabilidade da genitora, ao passo que ao pai caberia o papel de provisão. Observa-se que, nos casos de separação conjugal, especialmente quando as famílias protagonizavam situações de litígio, era comum uma postura e um discurso baseados na lógica adversarial, quando emerge a conjugalidade conflituosa de modo a colocar o(s) filho(s) no centro da disputa. Sendo assim, quando se tratava de um pedido de guarda unilateral, o duelo entre pais e mães manteve a mulher no lugar prioritário para a efetivação do exercício de cuidado, o que Barros (2001) denomina primado materno. Para a autora, foi especialmente a partir da promulgação da Lei do Divórcio (Lei n 6.515 de 1977) que atribuiu a guarda preferencialmente à genitora, nos casos em que ambos os pais fossem responsáveis pelo fim da relação conjugal - que se fortaleceu, nas famílias separadas, o papel social da mulher como sendo de melhor cuidadora.

Brito (2007) ressalta que, até meados da década de 1960, a mulher era considerada "rainha do lar", portanto responsável pelo cuidado dos filhos, e o homem era o provedor das necessidades familiares e chefe de família, termo que foi abolido com a Constituição de 1988, que reconheceu a igualdade de direitos e deveres entre homens e mulheres. Apesar disso, os efeitos sociais promovidos pela diferença de gênero permanecem no imaginário social e consequentemente promovem, ainda, o mito da supremacia materna.

Percebe-se que o peso dos modelos de provisão e cuidado atrelados aos papéis sociais de homem e mulher foi se fazendo presente nos textos da lei (Código Civil dos Estados Unidos do Brasil - Lei n 3.071 de 1916; Dispõe sobre a situação jurídica da mulher casada - Lei n 4.121 de 1962; Institui o Código Civil - Lei n 10.406 de 2002; Regula os casos de dissolução da sociedade conjugal e do casamento, seus efeitos e respectivos processos, e dá outras providências -
Lei $n^{\circ} 6.515$ de 1977) e, com isso, observa-se a corroboração dos moldes sociais para os papéis que ambos exercem no seio da família, com repercussões ainda hoje. Com a mulher possuindo a prioridade em relação à guarda dos filhos em caso de separação conjugal, torna-se evidente a diminuição do contato e participação do pai nas questões relativas à vida cotidiana dos filhos. 0 conceito de instinto materno ajudou a reforçar tal paradigma sobre os papéis sociais que envolvem a paternidade e a maternidade (Badinter, 1980; 2011), uma vez que fortaleceu o lugar da mulher na esfera doméstica como sendo uma pessoa cuidadora e zelosa, responsável pelo cuidado não apenas dos filhos, mas também do marido e da casa. Para Donzelot (1980), a ascensão da mulher ao lugar de cuidado só foi possível a partir da aproximação ou aliança entre a medicina, a mulher e o Estado que, juntos, promoveram a valorização da mulher/mãe por meio do enaltecimento do trabalho doméstico, o que contribuiu também para o reconhecimento do saber médico, doravante compreendido como um saber científico. Já para Costa (1979), o controle social, que anteriormente era exercido pela Igreja Católica, no Brasil, foi progressivamente sendo substituído por práticas estatais normatizantes, especialmente as de cunho sanitarista que exigiam o asseio do corpo, da casa e da sexualidade a partir de tecnologias de subjetivação - produção de modos de existência - empreendidas pela medicina social/sanitária.

Rago (2017) ressalta que o lugar de esposa-mãe-dona-decasa forjou uma representação simbólica da mulher que exigiu a tutela da família para a emancipação da cidade, especialmente para a utilização das camadas pobres da população como força de trabalho industrial. Para isso, foi necessário também a moralização dos hábitos e costumes que, por sua vez, revelou o modelo de organização familiar nuclear burguês. A colonização da mulher, que teve início com as classes abastadas, contou com o saber médico e teve a família como lugar de inscrição deste saber, produzindo, no campo social, o controle ético e moral, e tendo como horizonte o controle do corpo feminino e da sua sexualidade.

Os reflexos desta nova organização familiar não poderiam passar distantes da instituição judiciária. Para Barros (2001) e para Brito (2014), a prioridade da guarda materna pode ser observada no Direito de Família que, desde a promulgação do primeiro Código Civil, em 1916, direcionou os cuidados com as crianças às mulheres, lembrando que, naquela época, o casamento era indissolúvel. Na legislação específica (Lei $n^{\circ}$ 3.071 de 1916), a guarda dos filhos seria atribuída ao genitor que não tivesse dado causa à separação - de corpos, apenas. No entanto, nos casos em que ambos os genitores fossem responsáveis pela separação conjugal, os filhos do sexo masculino ficariam com as mães até os 6 anos de idade período de extenso cuidado físico, geralmente atribuído à muIher - e depois iriam ficar aos cuidados do pai. Já as filhas 


\section{- INTERACÃO EM ET PSICOLOGIA}

permaneceriam sob os cuidados maternos, independentemente da idade delas.

Em 1962, com o chamado Estatuto da Mulher Casada (Lei $\mathrm{n}^{\circ} 4.121$ de 1962), ficou instituído que nos casos de desquite judicial, os filhos menores permaneceriam com o cônjuge inocente. Contudo, em caso de responsabilidade conjunta pelo fim da relação conjugal, os filhos permaneceriam em poder da mãe. Tal entendimento esteve presente também na Lei do Divórcio (Lei n6.515 de 1977) e perdurou até a promulgação do mais recente Código Civil (Lei no 10.406 de 2002), quando foi instituído o novo critério para a definição da guarda unilateral. Neste caso, caberia ao genitor "melhor habilitado" a responsabilidade pelos cuidados cotidianos com os filhos, restando ao outro genitor a fiscalização da educação das crianças e as visitas quinzenais que, por sua vez, os distanciavam de uma sólida relação afetiva com o(s) filho(s).

Para Shine (2010), houve foi o reforço da ideia de mulher como melhor cuidadora ou melhor habilitada para os cuidados cotidianos com a prole e, com isso, a exacerbação da disputa por meio de um extenso trabalho de desqualificação do outro genitor, que solicita a guarda dos filhos. A luta pela guarda envolvia provar na Justiça quem era o genitor melhor habilitado para cuidar das crianças, contribuindo para o prolongamento do litígio conjugal (Antunes, Magalhães, \& FeresCarneiro, 2010).

Estudos do Instituto Brasileiro de Geografia e Estatística (IBGE - 2015) apontam que o percentual de homens que ficam com a guarda unilateral é reduzido. No entanto, este número vem crescendo. Entre 2014 e 2015, o número de guarda compartilhada subiu de $7,5 \%$ para $12,9 \%$. No Brasil, a taxa de guarda exclusiva materna chega a $78,8 \%$. Mas na Região Sudeste, por exemplo, que concentra uma das maiores taxas de guarda unilateral materna, a porcentagem chega a $81,1 \%$. Os pais ficam com $4,4 \%$ das guardas unilaterais e o quantitativo de compartilhamento da guarda gira em torno de $11,8 \%$. Em todas as Unidades da Federação, pode ser observado o predomínio de mulheres responsáveis pela guarda dos filhos menores, chegando a 91,4\% em Sergipe. No Amapá, do total de divórcios com filhos menores, 12,9\% apresentou guarda concedida ao homem sendo essa a maior proporção entre todas as Unidades da Federação. Observa-se que a concessão de guarda unilateral ainda predomina sobre o modelo de compartilhamento mesmo após a promulgação de duas legislações sobre guarda compartilhada, as leis $\mathrm{n}^{0} 11.698$ de 2008 e n¹3058 de 2014. As mulheres ainda detêm a hegemonia da responsabilidade pela guarda dos filhos menores, embora seja possível observar mudanças no compartilhamento dos cuidados parentais de modo mais amplo, com o aumento da participação do pai (Matos, Magalhães, FéresCarneiro, \& Machado, 2017).
As mudanças na legislação específica sobre Direito de Família, desta forma, foram fundamentais para a construção simbólica dos lugares de pai e mãe, não apenas na esfera da Justiça, mas no campo social, constituindo uma espécie de apoio sócio-jurídico para as mudanças do que, na atualidade, denominam-se novas formações familiares (Brandão, 2011; Hurstel, 1999). Para Brito (2014), a separação conjugal pode trazer para todos os componentes da família o sentimento de perda e, neste sentido, a guarda compartilhada pode ser uma saída para que os filhos não se afastem de seus genitores. A noção de guarda compartilhada surgiu da necessidade de se reequilibrar os papéis parentais, uma vez que a guarda unilateral foi sendo sistematicamente concedida à mãe, excluindo os genitores homens do papel de cuidador.

Sabe-se que a guarda compartilhada funciona bem quando os ex-cônjuges conseguem manter uma convivência pacífica (Gadoni-Costa, Frizzo, \& Lopes, 2015). No entanto, conforme legislação vigente (Altera os arts. 1.583, 1.584, 1.585 e 1.634 da lei $n^{0} 10.406$ de 10 de janeiro de 2002 [Código Civil], para estabelecer o significado da expressão "guarda compartilhada" e dispor sobre sua aplicação - Lei n¹3.058 de 2014), o estabelecimento desta modalidade de não está condicionado ao bom relacionamento ou ao acordo entre os pais. Neste sentido, alguns autores (Brito, 2014; Brandão, 2011) defendem que a guarda compartilhada deva ser determinada justamente nos casos em que um genitor introduz obstáculos à participação daquele que não possui a guarda, de modo a definir que a relação com a criança deva ser mantida com ambos. Ressalta-se que a legislação foi criada justamente para os casos em que há litígio conjugal e a convivência com os filhos é prejudicada devido aos conflitos entre os pais.

Alves, Cúnico, Arpini, Smaniotto e Bopp (2014) apontam a mediação como importante ferramenta para possibilitar o diálogo nos casos que envolvem conflitos familiares. Com isso, seria possível a construção de soluções capazes de atender aos interesses de pais e filhos, especialmente quanto ao estabelecimento da guarda compartilhada, evitando, assim, a compulsoriedade judicial, que obriga os pais a uma modalidade de guarda sem que o diálogo possa ser viabilizado. Tais soluções contribuiriam para resguardar os interesses e a saúde emocional da(s) criança(s).

A recente lei de $n^{\circ} 13058$ de 2014 pretende ampliar a convivência entre pais e filhos e torna a guarda compartilhada não mais uma opção, mas um modelo prioritário de guarda, sendo o padrão unilateral de guarda ainda possível, mediante anúncio de um dos genitores pelo desejo de utilizá-la. Desta forma, a legislação tornou a guarda compartilhada automatizada, o que significa um avanço no que tange ao compromisso social com a igualdade parental. No entanto, a 


\section{- INTERACÃO EM EF PSICOLOGIA}

automatização da guarda compartilhada pode significar também uma obrigatoriedade jurídica que desconsidera os interesses da criança, uma vez que os desentendimentos entre os genitores e a exacerbação da lide pode ser acentuada à medida que os pais não conseguem entrar em acordo em relação à administração dos cuidados com os filhos.

Destaca-se que o sistema jurídico brasileiro, ao incorporar uma legislação específica sobre a guarda compartilhada, reconhece que toda criança tem o direito de crescer junto à família. Esta garantia foi prevista no Estatuto da Criança e do Adolescente (ECA - Lei nº 8.069 de 1990), que destaca que toda criança ou adolescente tem o direito de ser criado e educado no seio da sua família, sendo-lhe assegurada a convivência familiar e comunitária. Diante do exposto, este estudo tem por objetivo principal investigar as repercussões da prio- ridade da guarda materna e o papel da guarda compartilhada como alternativa para a convivência familiar.

\section{MÉTODO}

Participaram desta pesquisa 12 sujeitos, dez homens e duas mulheres que romperam o laço conjugal há no mínimo um ano e no máximo dez anos, e que fazem parte de comunidades virtuais que abordam os temas guarda compartilhada e alienação parental na rede social conhecida como facebook. As comunidades virtuais atuam como uma espécie de grupo de apoio para pais e mães que declaram ter sofrido ou estar sofrendo alienação parental, bem como para pais que brigam na justiça para obter a guarda compartilhada dos filhos.

\section{Tabela 1. Caracterização dos participantes}

\begin{tabular}{|c|c|c|c|c|c|c|}
\hline \multirow[t]{2}{*}{ Pais } & \multirow[t]{2}{*}{ Idade } & \multirow[t]{2}{*}{$\begin{array}{c}\text { Tempo de } \\
\text { união / } \\
\text { separação } \\
\text { (em anos) }\end{array}$} & \multicolumn{2}{|c|}{ Filhos } & \multicolumn{2}{|c|}{ Tipo de Guarda } \\
\hline & & & Sexo & Idade & Compartilhada & Exclusiva \\
\hline João & 39 & $2 ; 1$ & $F$ & 2 & - & Materna \\
\hline Eduardo & 43 & $7 ; 7$ & $\mathrm{M} ; \mathrm{F}$ & $12 ; 10$ & - & Materna \\
\hline Miguel & 54 & $10 ; 5$ & $\mathrm{~F}$ & 13 & - & Materna \\
\hline Mateus & 43 & $7 ; 6$ & M. & 12 & - & Materna \\
\hline Ernani & 52 & $6 ; 6$ & $F$ & 8 & - & Materna \\
\hline Renato & 39 & $7 ; 3$ & $\mathrm{M} ; \mathrm{F}$ & $9 ; 4$ & - & Materna \\
\hline Vinícius & 39 & $3 ; 2$ & $\mathrm{~F}$ & 3 & - & Materna \\
\hline Felipe & 41 & $7 ; 2$ & M & 14 & - & Materna \\
\hline Júlio & 36 & $1 ; 4$ & $F$ & 4 & - & Materna \\
\hline Patrícia & 39 & $17 ; 2$ & $\mathrm{~F} ; \mathrm{M} ; \mathrm{M}$ & $16 ; 12 ; 9$ & $\operatorname{sim}$ & - \\
\hline Otávio & 35 & $3 ; 3$ & $F ; F$ & $7 ; 4$ & - & Materna \\
\hline Eduarda & 40 & $7 ; 7$ & $F ; F$ & $14 ; 15$ & - & $\begin{array}{l}\text { F14 materna/ F15 } \\
\text { paterna }\end{array}$ \\
\hline
\end{tabular}


O convite para participar da pesquisa foi feito individualmente, por meio de mensagens instantâneas - Messenger. Informamos sobre os objetivos da pesquisa e sobre o procedimento de entrevista online. O projeto foi aprovado pelo Comitê de Ética em Pesquisa da Pontifícia Universidade Católica do Rio de Janeiro - PUC-Rio, todos os participantes assinaram o Termo de Consentimento Livre e Esclarecido e os nomes aqui apresentados são fictícios.

Como instrumento de investigação, utilizou-se uma entrevista online com roteiro semiestruturado, contendo questões abertas, composta por eixos temáticos relacionados a questões relativas à parentalidade e à guarda compartilhada. 0 texto dos entrevistados, registrado por meio do Messenger, foi submetido ao método de análise de conteúdo na sua vertente categorial temática (Bardin, 2011).

Das falas dos entrevistados emergiram diversas categorias de análise. Para alcançar os objetivos deste trabalho, foram discutidas as seguintes categorias: prioridade da guarda materna e guarda compartilhada como alternativa para a convivência familiar. As demais categorias foram discutidas em outros trabalhos.

\section{RESULTADOS E DISCUSSÃO}

\section{PRIORIDADE DA GUARDA MATERNA}

0 privilégio da guarda materna foi exposto como algo muito presente nas Varas de Família. A maior parte dos entrevistados narraram um sentimento de desqualificação da figura paterna pela justiça e o privilégio materno na obtenção da guarda unilateral. Para 11 dentre os 12 participantes da pesquisa, a mulher tem vantagens na obtenção do modelo exclusivo/unilateral de guarda, o que leva muitos pais a lutarem pela guarda compartilhada, já que esta seria a única opção na tentativa de reaproximação com os filhos após a separação.

O homem já entra na vara de família culpado (eu já entrei). A juíza que julgou a pensão disse-me claramente que só as mulheres sabem criar e que era justo que a menina ficasse com a mãe, pois já estava com ela. Portanto, o que importa é só a dor da mãe, nunca a do pai. A mulher leva vantagens, simplesmente por ser mãe e quase sempre se ouve a justificativa de que "só a mãe sabe criar" (Miguel).

O judiciário é muito corporativista com a mulher. Porque quando você entra no judiciário, você já é o culpado. É muito deficitário, o judiciário trata os homens como somente um número, o problema é que envolve uma criança e não tem um cuidado, é uma coisa exposta, sabe? Uma coisa totalmente desnecessária. Ela acionou a defensoria pública e eu fui conversar com a defensora pública e ela disse: "ho- mem aqui na minha delegacia não entra". Eu tive que fazer queixa na ouvidoria da defensoria pública. A responsável ligou na minha frente, chamou a atenção. As mulheres dizem que existe muito machismo e existe muito machismo, mas o feminismo impera. Você pode ver nesses órgãos, é só mulher que trabalha (Matheus).

Segundo Barros (2001), apesar dos inúmeros esforços no campo do Direito de Família, no Brasil, para assegurar direitos iguais a todos, especialmente a partir da reformulação constitucional em 1988 (Constituição da República Federativa do Brasil de 1988), os direitos e deveres de pais e mães seguiram sendo uma exceção quando o assunto diz respeito ao instituto da guarda que, ao longo dos anos, vem sendo sistematicamente deferida à mãe. Aos pais a guarda exclusiva seria cabível apenas nos casos em que pesasse sobre a mulher situações que permitissem dúvidas sobre sua conduta moral. Nessas situações excepcionais, o pai poderia gozar do direito de ter os filhos sob seus cuidados cotidianos. Caso contrário, sua presença e participação na vida dos filhos estariam restritas aos finais de semana, quinzenalmente. Além disso, destaca-se a percepção de discriminação de alguns participantes em relação à sua condição de figura paterna, quando os pais apresentam o desejo de cuidar dos filhos, como pode ser observado nas narrativas a seguir.

O pai sofre preconceito quando quer ficar com os filhos até no trabalho. É o privilégio da mãe que falei com você (Eduardo).

No processo na Vara de Família eu só posso te dizer uma coisa: eu me sinto injustiçado. Mas não é só o Judiciário, o Conselho Tutelar, a Delegacia, qualquer órgão que eu procuro hoje eu sinto a injustiça e discriminação por eu ser pai, entendeu? (Vinícius).

O sistema jurídico brasileiro tem menosprezado o exercício da paternidade ao supervalorizar os cuidados maternos e identificá-los como imprescindíveis se comparados aos cuidados paternos. Desta forma também há o silenciamento do direito da criança, ao afastá-la do convívio com um dos genitores. A manutenção da convivência com ambos os pais, prerrogativa fundamental dos direitos constitucionais, dependente, muitas vezes, da viabilização do acesso ao pai por parte da mãe (Barros, 2001).

Ao discutir sobre o mito do amor materno, Badinter (1980, 2011) ressalta que as políticas empreendidas sobre a maternidade tendem a enclausurar a mulher na função materna, deixando o homem/pai de fora desta relação, enaltecendo a díade mãe-bebê. Desta forma, desqualifica a importância do pai na formação social e subjetiva da criança. Para Brito (2008), a valorização da maternidade é resultado de uma série de fatores sociais que contribuíram para o entendimento 
de que a mulher estaria melhor capacitada para a administração dos cuidados físicos e emocionais dos filhos.

A maternidade adquiriu um outro sentido ao enriquecer a mãe de novos deveres e cuidados. A mulher, então, passa a ser considerada a auxiliar do médico nos cuidados físicos e a colaboradora do padre e do professor na formação moral e religiosa. Além disso, é responsável também pela formação psíquica dos filhos (Costa, 1979; Franco, 2013). Um aspecto importante a considerar, mediante as decisões judiciais que favorecem os cuidados maternos, é o fato de que a subjetividade do juiz se encontra entrelaçada aos costumes e, desta maneira, podem influir sobre suas decisões os valores educacionais, familiares e pessoais que compõem a sua formação social e subjetiva, assim como sua experiência política e jurídica influenciará em sua tomada de decisão (Almeida Prado, 2003).

Em contrapartida à supervalorização da maternidade nos cuidados físicos e emocionais na percepção dos participantes há também a supervalorização da paternidade no lugar de provisão dos filhos. A pensão alimentícia foi uma questão destacada na narrativa dos pais como um importante fator que demarca o lugar que eles deveriam ocupar na vida da criança.

As vezes ficamos tão cegos com relação a pagar uma pensão alta mesmo sem poder para que não sejamos tolhidos de conviver com nossos filhos (Otávio).

A própria sociedade faz esse controle, como se o amor de mãe fosse possível e o amor de pai não é. Parece que existe uma máquina que determina o valor de uma mãe, sempre colocam que o amor da mãe é superior ao amor paterno. $O$ pai deve pagar a pensão (Felipe).

A pensão, por sua vez, pode ser definida como uma quantia fixada pelo juiz e que deve ser de reponsabilidade de um dos genitores, o responsável pensioneiro. Ela é uma forma de garantir a manutenção dos filhos e um procedimento específico nas Varas de Família, um processo jurídico independente do processo de guarda. A expressão "pensão alimentícia" não corresponde apenas à subsistência de alimentos ao apensionado, mas está relacionado ao custo financeiro necessário para a manutenção da saúde, da educação, da alimentação e da moradia dos filhos, por exemplo. Os pais se queixam de que, em teoria, o pagamento da pensão alimentícia seja uma responsabilidade de ambos os pais. No entanto, tal processo jurídico é fortemente marcado pela figura do homem como principal responsável (Cúnico \& Arpini, 2014).

Para Lyra, Leão, Lima, Targino, Crisóstomo e Santos (2008) a hierarquização dos papéis sociais de homem e muIher é uma construção social, cultural e histórica. Para os autores, o cuidado na relação com os filhos compreende desigualdades amplamente demarcadas pela dicotomia paiprovedor-protetor e mãe-cuidadora ou líder expressiva-afetiva nas famílias. No entanto, observam-se, na atualidade, diferentes modalidades de exercício da paternidade, o que requer a presença e participação ativa dos pais na vida dos filhos e não mais a restrição ao papel de provedor.

O pai pode demonstrar maior envolvimento na educação e no cuidado com os filhos de qualquer faixa etária: ele pode contribuir na alimentação, com a troca de fraldas, na visita ao médico, nas idas à escola, a passeios, pode colocar os filhos para dormir, conversar sobre o primeiro beijo ou sobre a primeira relação sexual. Isto posto, deve-se reconhecer a paternidade não como uma obrigação, mas como algo que alude à dimensão do desejo, o que implica em um compromisso (Lyra et al., 2008). Para Kaufman (1995), a transformação dos papéis sociais de pai e mãe precisa ainda passar por mudanças em três dimensões: no campo dos direitos e das instituições, na unidade do trabalho doméstico - o que exige maior participação dos pais no cuidado com a casa - e no cuidado com as crianças.

Considera-se que o reconhecimento da paternidade, no âmbito social e cultural, e da capacidade do pai de exercer o cuidado dos filhos pode ter repercussões também no campo da justiça, que poderia retirá-lo do lugar predominante de provisão em casos de separação conjugal. Como aponta Hurstel (1999), pai e mãe devem possuir direitos e deveres iguais em relação aos filhos, mesmo que não permaneçam casados. Para isso, as instituições devem oferecer as ancoragens sociais necessárias ao processo de transmissão, característicos da função parental.

\section{GUARDA COMPARTILHADA COMO ALTERNATIVA PARA A CONVIVEENCIA FAMILIAR}

A guarda compartilhada como alternativa para a convivência familiar é um tema presente na narrativa da maioria dos pais entrevistados. Para a maior parte dos entrevistados, conseguir junto à justiça o compartilhamento da guarda do(s) filho(s) representa ainda uma das maiores dificuldades enfrentadas pelos que desejam manter os vínculos socioafetivos com os filhos após o rompimento da relação conjugal.

Dentre as principais questões relatadas, apareceram no discurso dos sujeitos a dificuldade dos genitores do sexo masculino quanto a participar da vida cotidiana dos filhos e ter convivência com as crianças. Uma das estratégias para vencer esse obstáculo foi a busca pela manutenção dos laços parento-filiais por meio da luta pela guarda compartilhada. Nesse contexto, o afastamento entre pais e filhos foi relatado como a maior consequência da separação.

A ideia de que a guarda compartilhada deveria incluir a divisão igualitária do tempo da criança com ambos os pais foi 


\section{W NTERAC̄OOEM ET PSICOLOGIA}

Débora Augusto Franco, Andrea Seixas Magalhães e Terezinha Féres-Carneiro

algo amplamente comentado pela maioria dos sujeitos entrevistados, como evidenciado nas falas de Júlio e Renato:

A guarda compartilhada, a gente defende que se dê de forma igualitária para ambos os genitores. Seriam direitos e deveres de $50 \%$ a $50 \%$, independente do grau de litígio porque a lei prevê. O ideal é 50, 50\% do tempo de convívio que seria a custódia física da criança (Júlio).

Acho que deveria ser 15 dias com o pai e 15 dias com a mãe. Acho que esse seria o ideal a ser buscado. Eu defino a guarda compartilhada como um meio de diminuição do litígio instalado entre os dois genitores e o bem-estar da criança que, comprovadamente vai viver em harmonia com as duas educações e isso dependendo das condições fáticas que a lei prevê (Renato).

Observa-se que, para ambos os entrevistados, a divisão igualitária do tempo com a criança é referida ao modelo de guarda alternada, no qual um dos genitores é responsável absoluto pela criança no período em que ela esteja sob seus cuidados. Esse tipo de guarda implica em alternância da convivência com os pais a cada 15 dias ou de acordo com a determinação do juiz. Ou seja, a responsabilidade sobre a criança se dá apenas durante o período estipulado pela justiça em que um dos genitores é o responsável ou guardião. Fora do período previsto pela decisão judicial, em geral, não há contato do outro genitor com o filho, cessando sua responsabilidade sobre a criança/adolescente.

Destaca-se que a guarda alternada acaba prejudicando a convivência familiar, uma vez que dificulta a comunicação entre a criança e o genitor que não está responsável pelos seus cuidados naquele período estipulado. Além disso, não há previsão legal no ordenamento jurídico brasileiro para a modalidade de guarda alternada. Quatro pais entrevistados, contudo, consideram essa alternativa. Por outro lado, alguns destacam a importância do diálogo entre os genitores. Para estes, o diálogo saudável entre os ex-cônjuges é fundamental para que a guarda compartilhada possa se concretizar efetivamente.

Acho que a guarda compartilhada só daria certo se tivesse um diálogo dela comigo, sem usar os filhos e com o interesse só do bem deles (Eduardo).

Em primeiro lugar na minha opinião precisa de uma boa comunicação para a guarda compartilhada, coisa que não tenho...Nenhuma comunicação, zero (Renato).

A falta de diálogo entre os pais é prejudicial para a qualidade da interação entre pais e filhos após a separação conjugal e, certamente, capaz de promover obstáculos à convivência familiar. Segundo Dantas, Jablonski e Féres-Carneiro (2004), o afastamento entre pais e filhos após a separa- ção conjugal é resultado de uma série de mudanças na rotina familiar que podem afetar a qualidade do relacionamento e do exercício de parentalidade. Para os autores, a manutenção dos laços afetivos entre pais e filhos depende da convivência, no entanto, não é possível aferir o tempo ideal que cada criança ou adolescente deveria experimentar de convivência com os pais. Em outras palavras, seria possível delimitar a quantidade de tempo suficiente para a manutenção dos laços afetivos entre pais e filhos? Como mensurar esse tempo? Ainda segundo os autores, é preciso que haja um intercâmbio no exercício das funções materna e paterna, algo difícil de ser manejado entre sujeitos que não conseguem manter uma relação de diálogo. No entanto, é preciso reconhecer que, cada vez mais as mudanças no contexto da família apontam para o fato de que o pai e a mãe devem ser igualmente responsáveis pelos cuidados, bem-estar e provisão dos filhos (Cúnico \& Arpini, 2013; 2014). Sobre as dificuldades de manutenção das relações de afeto com os filhos em função de um relacionamento de pouca comunicação entre os pais, alguns entrevistados destacaram que, para uma melhor qualidade do exercício da guarda compartilhada, seria necessário que ambos os pais priorizassem os filhos.

Nos relatos dos pais as queixas também incidem, com frequência, sobre as mudanças na rotina familiar que, em função do término da relação, afetam a presença e participação de um dos ex-parceiros na rotina dos filhos.

Antes nós fazíamos tudo junto, desde andar de carrinho de rolimã, assistir filme, jogar bola, brincar de luta. Eu lembro assim eu sempre fui muito participativo com ele. Porque eu já fui moleque e eu tive muitas dificuldades com meu pai, meu pai era muito ausente, entendeu? (Matheus).

No início, neste $1^{\circ}$ ano não mudou em nada a minha convivência com as minhas filhas. Eu as levava na escola, ele estava sempre por perto e ajudando. O problema foi que ele passou a morar na casa da mãe dele, há mais ou menos $100 \mathrm{~km}$ da minha casa e levou as meninas para morar com ele na casa da mãe dele. Elas ficaram três anos com ele nessa situação. Se afastaram de mim esse tempo todo e isso foi muito ruim para nossa relação. Fiquei 3 anos sem ver as minhas filhas (Eduarda)

Pesquisas apontam o afastamento do pai como a maior consequência da separação conjugal (Brito, \& Gonsalves, 2013; Brito, 2014; Cúnico, \& Arpini, 2013). Este afastamento após o desenlace conjugal é uma constante neste novo rearranjo familiar. $\mathrm{O}$ afastamento de um dos pais é uma característica da guarda unilateral, que favorece a presença apenas daquele genitor que permaneceu com a guarda, podendo ser o pai ou a mãe. Há sérias repercussões na convivência familiar neste caso, especialmente quando esta convivência entre pais e filhos se torna reduzida aos finais de semana (Oliveira 
e Brito, 2016). Em pesquisa sobre a visão dos filhos acerca da separação dos pais, Brito (2007) destacou que não apenas havia o afastamento do genitor não guardião, geralmente o pai, mas também o afastamento de toda a família paterna.

De acordo com o relato dos pais entrevistados, a referência feita à modificação de rotina inclui as mudanças de horários das atividades a que as crianças estavam habituadas, como também no contato mais estreito com os filhos no cotidiano, o que se torna um privilégio do genitor guardião. Pesquisas com filhos de pais que não coabitam (Brito, 2007; Cúnico \& Arpini, 2013; 2014) apontam que a fixação de visitas, especialmente de forma quinzenal, além de contribuir para fragilizar a relação de afeto entre pais e filhos, ocasiona uma evidente mudança na rotina das crianças que, anteriormente, estavam acostumadas ao convívio diário com ambos os pais.

Maldonado-Durá e Millhuff (2004) afirmam que nos EUA, a lei não leva em conta o interesse da criança e mesmo crianças muito pequenas são tratadas, consequentemente, por efeito de legislação, como "uma propriedade" dos pais. Brito e Gonsalves (2013) ressaltam que no Brasil, a noção de guarda compartilhada deve ir além da preocupação com dias, horários e formas de deslocamento das crianças e dos pais. Ao se determinar a guarda compartilhada, ressalta-se a importância que o Estado atribui à convivência familiar e comunitária da criança.

Os genitores destacaram também o papel do judiciário no afastamento dos pais que não ficaram com a guarda. Para os entrevistados, o prolongamento do processo judicial sobre guarda e visitação, ou seja, a morosidade da justiça, contribui para o afastamento de um dos genitores do convívio com os filhos. Desta forma, para a maioria dos entrevistados, a angústia de ter os filhos afastados do cotidiano de vida só poderia ser suprida por meio da convivência ampliada, algo que deveria ser garantido pelo Poder Judiciário, especialmente a partir da promulgação da legislação específica em 2014 (Altera os arts. $1.583,1.584,1.585$ e 1.634 da lei $n^{0} 10.406$ de 10 de janeiro de 2002 [Código Civil], para estabelecer o significado da expressão "guarda compartilhada" e dispor sobre sua aplicação - Lei $n^{\circ}$ 13.058). Para os genitores, caberia à justiça a administração dos conflitos e a garantia desta aproximação entre pais e filhos por meio da guarda compartilhada, contudo, a restrição de convivência com os filhos é algo que se institui logo no início do processo de separação conjugal, muitas vezes acompanhada por uma suspeita de que o genitor afastado é incapaz de cuidar dos próprios filhos. A maioria dos pais afirmaram que foram afastados da rotina de cuidados com os filhos, especialmente nos primeiros dias e/ ou meses logo após tomada a decisão pela separação. Os pais responsabilizam a justiça pela demora no andamento do processo, que amplia o tempo de espera pela reaproximação com os filhos, prejudicando o relacionamento e o direito à convivência familiar.

O judiciário deveria informar, esclarecer e ser mais ágil em casos assim. Não é justo deixar os filhos sem contato com os pais durante esse tempo todo (Eduarda).

E o judiciário, simplesmente não tá nem aí. Que nem esses afastamentos bruscos que tem, impedimento de visita, o pai não tem contato com os filhos. Eu acho que deveria fazer o seguinte, deveria ser automático. 0 cara se separou da esposa, chega na frente do juiz, é guarda compartilhada, tempo integral para cada um direitinho. Dividir as tarefas, as obrigações. E não afastar para apurar se o cara tem condições, se não tem condições. A minha filha queria estar com os dois juntos, mas se os dois não tem como viver junto, tem que conviver, tem que ter o contato, tanto com o pai quanto com a mãe, não tem porque esse afastamento (Ernani).

Observa-se que a intervenção judicial na mediação de conflitos é lenta especialmente por prever incontáveis possibilidades de recursos que retardam as decisões (Sales \& Chaves, 2014). A opção pelo afastamento da criança de um dos genitores pode levar a um distanciamento expresso por um tempo irrecuperável e que, na história de vida de uma criança ou adolescente, pode representar, por exemplo, o sentimento de abandono. Ademais, há o acúmulo de processos e burocracias que acabam por afetar a vida daqueles que dependem de decisões da justiça para a reorganização da vida familiar. Para Adorno e Pasinato (2007), a morosidade da justiça está relacionada à dificuldade de administrar um tempo que, se longo, pode representar a incapacidade institucional em corrigir falhas técnicas na condução administrativa dos procedimentos. Se muito curto, corre-se o risco de suprimir direitos consagrados na Constituição, instituindo, em lugar da justiça, a injustiça. Além disto, destaca-se a falta de recursos humanos para o melhor encaminhamento das situações apresentadas à justiça. Pellegrini e Simioni (2015) ressaltam que há um esgotamento do Poder Judiciário, o que denota a urgência e a necessidade de busca por novas ações que modifiquem a verticalidade do poder decisório e a centralização do juiz-poder imposta pelo ordenamento jurídico brasileiro.

Schneebeli e Menandro (2014) ressaltam que a presença e participação de ambos os pais na vida dos filhos é de extrema importância para o desenvolvimento infantil, o que só pode ser construído a partir da convivência familiar. Para os autores, quando as mudanças na rotina da família afetam o cotidiano dos filhos, estes podem sentir-se inseguros emocionalmente e, muitas vezes, deslocados ou abandonados. Para Passos (2013), o modo como os filhos vivenciam o período inicial após a separação depende, substancialmente, da ma- 


\section{W'INTERACÃO EM PSICOLOGIA}

Débora Augusto Franco, Andrea Seixas Magalhães e Terezinha Féres-Carneiro

neira como seus pais negociam o término da vida conjugal, do modo como separam a relação de conjugalidade da relação de parentalidade e da maneira como administram os conflitos oriundos da relação amorosa e da convivência familiar após a separação conjugal. Para a autora, nos relacionamentos familiares contemporâneos o diálogo e a negociação são priorizados, tanto entre os membros do casal, quanto na relação com os filhos. Ela pontua, contudo, que com o desenlace conjugal as coisas mudam e a comunicação e a negociação podem não mais sustentar a dinâmica das relações.

Para Gadoni-Costa, Frizzo e Lopes (2015), a guarda compartilhada seria uma saída possível para a promoção da convivência entre pais e filhos, na qual os pais deveriam continuar dividindo as responsabilidades e os cuidados com a prole e também compartilhando as decisões sobre suas vidas. A separação do casal não implica em término da família, e sim na transformação desse sistema, que se mantém como organização, apesar da díade parental não formar mais um casal conjugal.

\section{CONSIDERAÇÕES FINAIS}

A separação conjugal pode trazer para todos os componentes da família o sentimento de perda e a guarda compartiIhada pode ser uma saída para que os filhos não se afastem de seus genitores. Contudo, destaca-se que a legitimação dos cuidados parentais, por meio da busca pela convivência ampliada após a separação conjugal, não depende apenas de leis específicas e da atuação do Poder Judiciário. É fundamental, para a proteção de crianças e adolescentes, romper com a ideia arraigada em nossa cultura de que deve haver, em casos de separação conjugal, um genitor principal, o guardião, e um genitor secundário, o visitante. Para isso, o direito dos filhos à convivência familiar deve prevalecer sobre os conflitos da conjugalidade e sobre os interesses dos ex-cônjuges (Brito, 2014; Gadoni-Costa, Frizzo \& Lopes, 2015; Schneebeli \& Menandro, 2014).

Constatamos, a partir das narrativas, que os pais entrevistados demonstram desejo de participar mais do cotidiano dos filhos. No entanto, em casos de separação conjugal, ainda prevalece o modelo de guarda exclusiva materna e, com isso, o afastamento do genitor não guardião. Consequentemente, tem se ampliado o número de homens que lutam na justiça para obter a guarda compartilhada dos filhos.

Conclui-se, a partir dos depoimentos dos entrevistados, que a prioridade da guarda materna conserva elementos sociais, culturais e históricos que associam à imagem da muIher a qualidade de cuidadora, o que favorece as mães nos processos judiciais de disputa pela guarda dos filhos. Contudo, ressalta-se que a luta pela guarda compartilhada, na mai- or parte dos relatos, corresponde a uma alternativa possível para a convivência familiar. Para isso, é preciso construir suportes sociais, culturais, jurídicos e políticos que possam desmontar o estereótipo da mulher como cuidadora melhor habilitada, assim como do homem como auxiliar-provedor principal nos cuidados direcionados aos filhos.

É necessário criar políticas de conscientização dos pais quanto à importância da manutenção da convivência familiar após o divórcio. Destacam-se alguns instrumentos utilizados pelo Poder Judiciário brasileiro, tais como a Cartilha do Divórcio (2013), a Cartilha Guarda Compartilhada (2011) e a CartiIha da Família (2011). A Cartilha do Divórcio (2013), por exemplo, que foi criada pela Escola Nacional de Mediação e Conciliação (ENAM) e pelo Conselho Nacional de Justiça $(\mathrm{CNJ})$, é destinada a públicos distintos e possui dois modelos. 0 primeiro é direcionado aos pais, orientando-os quanto aos filhos em situação de divórcio dos pais. 0 segundo modelo é direcionado aos filhos adolescentes, orientando-os em relação à construção de um relacionamento saudável com ambos os pais após o divórcio. No entanto, destaca-se que tais políticas de conscientização, no Brasil, estão restritas ao ambiente jurídico e, desta forma, são limitadas quanto à promoção de mudanças socioculturais, especialmente no que tange aos modos de ser pai e mãe na contemporaneidade. Os debates sobre a parentalidade precisam habitar os diversos espaços onde as famílias circulam, como a escola, as instituições de saúde, e outras. Acredita-se que, desta forma, as ancoragens sociais necessárias estarão melhor estruturadas para que as famílias possam gerir as dificuldades que surgem no relacionamento parento-filial após a separação conjugal.

Além disso, as práticas de mediação familiar também podem favorecer o diálogo entre os ex-cônjuges, esclarecendo aos pais sobre a importância da manutenção dos vínculos parentais após o fim da relação amorosa, rompendo com a ideia de provisão e cuidado atrelados às figuras de pai e mãe, respectivamente. Para isso, faz-se importante também um trabalho interdisciplinar, envolvendo as equipes do Poder Judiciário, profissionais da Psicologia, do Serviço Social e do Direito que, alinhados em prol do melhor interesse da criança, possam oferecer às famílias as ferramentas necessárias para o diálogo e para a cooperação na busca pela resolução dos conflitos característicos da lide.

Destaca-se a necessidade de ampliação do debate sobre o tema e da busca de interlocução com diversas áreas de conhecimento. Acredita-se que a presente investigação contribui com subsídios para intervenções junto a famílias em litígio com vistas à melhor qualidade da convivência com os pais, à ampliação do diálogo, à promoção a saúde mental e da qualidade de vidas de crianças, adolescentes e das famílias pós-divórcio. 


\section{H NTERAC̄̈OEM PSICOLOGIA}

\section{DECLARAÇÃO DA CONTRIBUIÇÃO DOS AUTORES}

D.A.F e A.S.M contribuíram para a conceitualização, investigação, discussão dos dados e para a redação final (revisão e edição) do artigo; T.F-C contribuiu para a conceitualização, discussão dos dados e para a redação final (revisão e edição).

\section{DECLARAÇÃO DE CONFLITOS DE INTERESSE}

Os autores declaram que não há conflitos de interesse no manuscrito submetido

\section{FINANCIAMENTO}

A pesquisa que originou o manuscrito foi financiada parcialmente pela Bolsa de doutoramento da primeira autora (CAPES/PROSUP) e pelas Bolsas de Produtividade em Pesquisa CNPq da segunda e da terceira autora.

\section{REFERÊNCIAS}

Adorno, S. \& Pasinato, W. (2007). A justiça no tempo, o tempo da justiça. Tempo Social, 19(2), 131-155. https://dx.doi.org/ 10.1590/S0103-20702007000200005.

Almeida Prado, L. R. (2003). Neutralidade e imparcialidade dos juízes? Em G. Groeninga, \& R. C. Pereira (Orgs). Direito de família e psicanálise: Rumo a uma nova epistemologia (pp. 301-309). Rio de Janeiro: Imago.

Alves, A. P., Cúnico, S. D., Arpini, D. M., Smaniotto, A. C., \& Bopp, M. E. T. (2014). Mediação familiar: Possibilitando diálogos acerca da guarda compartilhada. Pesquisas e Práticas Psicossociais, 9(2), 193-200.

Antunes, A. L. M. de P., Magalhães, A. S., \& Feres-Carneiro, T. (2010). Litígios intermináveis: Uma perpetuação do vínculo conjugal? Aletheia, 31(1), 199-211.

Badinter, E. (1980). Um amor conquistado: O mito do amor materno. Rio de Janeiro: Editora Nova Fronteira.

Badinter, E. (2011). O conflito: A mulher e a mãe. Rio de Janeiro: Record.

Bardin, L. (2011). Análise de conteúdo. São Paulo: Edições 70.

Barros, F. O. (2001). Do direito ao pai. Belo Horizonte: Del Rey.

Brandão, E. P. (2011). A interlocução com o direito à luz das práticas psicológicas em Varas de Família. Em H. S. Gonçalves \& E. P. Brandão (Orgs.). Psicologia Jurídica no Brasil (pp.51-97). Rio de Janeiro: Nau Editora.

Brito, L. M. T. (2007). Família pós-divórcio: A visão dos filhos. Psicologia Ciência e Profissão, 27(1), 32-45. https:// dx.doi.org/10.1590/S1414-98932007000100004
Brito, L. M. T. (2014). Rupturas familiares: Olhares da psicologia jurídica. Em M. D. Arpini, \& S. D. Cúnico (Orgs.), Novos Olhares Sobre a Família: Aspectos psicológicos, sociais e jurídicos (pp. 55-70). Curitiba: CRV.

Brito, L. M. T., \& Gonsalves, E. N. (2013). Guarda Compartilhada: Alguns argumentos e conteúdos da jurisprudência. Revista Direito GV, 9(1), 299-317. https://dx.doi.org/10.1590/ S1808-24322013000100011

Constituição da República Federativa do Brasil, do Diário Oficial da União de 5 de outubro de 1988, §1. Recuperado de http://www.planalto.gov.br/ccivil_03/constituicao/constituicao.htm

Costa, J. F. (1979) Ordem médica e norma familiar. Rio de Janeiro: Editora Graal.

Cúnico, S. D., \& Arpini, D. M. (2013). O afastamento paterno após o fim do relacionamento amoroso: Um estudo qualitativo. Interação em Psicologia, 17(1), 99-108.

Cúnico, S. D., \& Arpini, D. M. (2014). Não basta gerar, tem que participar? Um estudo sobre a ausência paterna. Psicologia: Ciência e Profissão, 34(1), 226-241. https://dx.doi.org/ 10.1590/S1414-98932014000100016

Dantas, C., Jablonski, B., \& Féres-Carneiro, T. (2004). Paternidade: Considerações sobre a relação pais-filhos após a separação conjugal. Paidéia, 14(29), 347-357. https:// dx.doi.org/10.1590/S0103-863X2004000300010

Donzelot, J. (1980). A polícia das famílias. Rio de Janeiro: Editora Graal.

Franco, D. A. (2013). Maternidade e amamentação: Engrenagens político-sociais na fabricação de famílias desviantes. Mnemosine, 9(1), 169-191.

Gadoni-Costa, L. M., Frizzo, G. B., \& Lopes, R. de C. S. (2015). A guarda compartilhada na prática: Estudo de casos múltiplos. Temas em Psicologia, 23(4), 901-912. https:// dx.doi.org/10.9788/TP2015.4-08

Hustel, F. (1999). As novas fronteiras da paternidade. Campinas: Papirus.

Instituto Brasileiro de Geografia e Estatística - IBGE (2015). Anuário Estatístico do Brasil. Rio de Janeiro: IBGE. Recuperado de http://biblioteca.ibge.gov.br/visualizacao/periodicos/20/aeb_2015.pdf

Kaufman, M. (1995). Los Hombres, el feminismo y las experiencias contradictorias del poder entre los hombres. Em L. G. Arango, M. León, \& M. Viveros (Orgs.), Género e identidad: nsayos sobre lo feminino y lo masculino (pp. 123146). Bogotá: Tecer Mondo/ Uniandes.

Lei n. 3.071 de $1^{\circ}$ de janeiro de 1916 §1.Código Civil dos Estados Unidos do Brasil. Recuperado de http://www.planalto.gov.br/ccivil_03/leis/l3071.htm

Lei n. 4.121 do Diário Oficial da União de 27 de agosto de 1962 §1. Dispõe sobre a situação jurídica da mulher casada. Recuperado de http://www.planalto.gov.br/ccivil_03/ leis/1950-1969//4121.htm 


\section{-4* INTERACÃO EM IT PSICOLOGIA}

Lei n. 6.515 de 26 de dezembro de 1977 §1 .Regula os casos de dissolução da sociedade conjugal e do casamento, seus efeitos e respectivos processos, e dá outras providências. Recuperado de http://www.planalto.gov.br/ccivil_03/leis/L6515.htm

Lei n. 8.069 do Diário Oficial da União de 13 de julho de 1990 $\S 1$. Estatuto da Criança e do Adolescente - ECA. Recuperado de http://www.planalto.gov.br/ccivil_03/leis/ I8069.htm

Lei n. 10.406 do Diário Oficial da União de 11 de janeiro de 2002. Institui o Código Civil. Recuperado de http:// www.planalto.gov.br/ccivil_03/leis/2002/l10406.htm

Lei n. 11.698 do Diário Oficial da União de 16 de junho de 2008 (2008). Altera os arts. 1.583 e 1.584 da Lei $n^{\circ}$ 10.406 de 10 de janeiro de 2002 - Código Civil para instituir e disciplinar a guarda compartilhada. Recuperado de http://www.planalto.gov.br/ccivil_03/_ato20072010/2008/lei/l11698.htm

Lei n. 13.058 do Diário Oficial da União de 23 de dezembro de 2014 (2014). Altera os arts. 1.583, 1.584, 1.585 e 1.634 da lei $\mathrm{n}^{0} 10.406$ de 10 de janeiro de 2002 (Código Civil), para estabelecer o significado da expressão "guarda compartilhada" e dispor sobre sua aplicação. Recuperado de http://www.planalto.gov.br/ccivil_03/_ato20112014/2014/lei/l13058.htm

Lyra, J., Leão, L. S., Lima, D. C., Targino, P., Crisóstomo, A., \& Santos, B. (2008). Homens e cuidado: Uma outra família? Em A. R. Acosta, \& M. A. F. Vitale (Orgs.). Família: Redes, laços e políticas públicas (pp.79-91). São Paulo: Cortez/ PUC SP.

Maldonado-Durá, M., \& Millhuff, C. (2004). A parentalidade nos Estados Unidos atualmente. Em M. C. Solis-Ponton (Org.), Ser pai, ser mãe: parentalidade: Um desafio para o terceiro milênio (pp 171-179). São Paulo: Casa do Psicólogo.
Matos, M. G., Magalhães, A. S., Féres-Carneiro, T., \& Machado, R. N. (2017). Construindo o vínculo pai-bebê: A experiência dos pais. Psico-USF, 22(2), 261-271. https://dx.doi.org/ 10.1590/1413-82712017220206

Oliveira, C. F. B., \& Brito, L. M. T. de. (2016). Humanização da justiça ou judicialização do humano? Psicologia Clínica, 28(2), 149-172.

Passos, M. C. (2013). Intimidade: origem na família e repercussões na clínica. Em T. Féres-Carneiro (Org.), Casal e Família: Transmissão, conflito e violência (pp 129-140). São Paulo: Casa do Psicólogo.

Pellegrini, C. P., \& Simioni, F. (2015). A Crise da Jurisdição no Estado Moderno, o Novo Código de Processo Civil e o Marco Legal da Mediação. Juris, 23(1), 123-139.

Rago, M. (2017). Do cabaré ao lar: A utopia da cidade disciplinar: Brasil 1890-1930. Rio de Janeiro: Paz e Terra.

Sales, L. M. M., \& Chaves, E. C.C. (2014). Mediação e conciliação judicial: A importância da capacitação e de seus desafios. Sequência, 69(1), 255-280. https://dx.doi.org/ 10.5007/2177-7055.2014v35n69p255

Schneebeli, F. C., \& Menandro, M. C. S. (2014). Com quem as crianças ficarão? Representações sociais da guarda dos filhos após a separação conjugal. Psicologia \& Sociedade, 26(1), 175-184. https://dx.doi.org/10.1590/S010271822014000100019

Shine, S. K. (2010). A espada de Salomão: A psicologia e a disputa de guarda de filhos. São Paulo: Casa do Psicólogo.

Recebido em 10.10.2017 Primeira Decisão Editorial em 20.11.2017 Aceito em 01.02.2018 